\title{
MODELING RADIATION-INDUCED SEGREGATION IN BINARY ALLOYS
}

\author{
R.V. Skorokhod ${ }^{1}$, O.M. Buhay ${ }^{2}$, V.M. Bilyk ${ }^{2}$, V.L. Denysenko ${ }^{2}$, O.V. Koropov ${ }^{2}$ \\ ${ }^{1}$ V.N. Karazin Kharkiv National University \\ 4, Svobody sq., 61022 Kharkiv, Ukraine \\ ${ }^{2}$ Institute of Applied Physics of NAS of Ukraine \\ 58, Petropavlivska St., 40030 Sumy, Ukraine \\ e-mail: r.skorokhodqq@gmail.com \\ Received January 26, 2018
}

\begin{abstract}
A computer code to calculate the time and space dependencies of the defect and component concentrations of a binary alloy is developed. This code is based on the theoretical model for radiation-induced segregation governed by first and second Fick's laws with taking into account inverse Kirkendall effect. The system of three coupled partial differential equations for concentrations of one of components and point defects is converted to the system of ordinary differential equations in time by a discretization procedure. Numerical solutions of this system are obtained under appropriate initial and boundary conditions by means of the MATLAB. The modeling of radiation-induced segregation in binary $\mathrm{Fe}-\mathrm{Cr}$ alloys is carried out for various initial concentrations of components, temperatures, dose rates and doses. The process of achievement of steady state at dose rising is demonstrated. The calculated concentration profiles are compared with experimental profiles published in literature. The sensitivity of model to input parameters is done and the capabilities of proposed model are estimated. This computer code for multicomponent alloys is developed.

KEY WORDS: materials of nuclear engineering, radiation-induced segregation, binary metal alloys, concentration profiles, point defects, inverse Kirkendall effect, balance equations, computer simulation

\section{МОДЕЛЮВАННЯ РАДІАЦІЙНО-ІНДУКОВАНОЇ СЕГРЕГАЦІЇ В БІНАРНИХ СПЛАВАХ Р.В. Скороход ${ }^{1}$, О.М. Бугай${ }^{2}$ В.М. Білик ${ }^{2}$, В.Л. Денисенко ${ }^{2}$, О.В. Коропов ${ }^{2}$ \\ ${ }^{1}$ Харківський національний університет імені В.Н. Каразіна майдан Свободи, 4, м. Харків 61022, Украӥна \\ ${ }^{2}$ Інститут прикладної фізики НАН України вул. Петропавлівська, 58, м. Суми 40030, Украӥна}

В моделі радіаційно-індукованої сегрегації, що базується на першому та другому законах Фіка з урахуванням оберненого ефекту Кіркендала, розроблений комп'ютерний код, за допомогою якого для бінарних сполук знайдені просторова і часова залежності концентрацій компонентів та точкових дефектів. Система трьох зв'язаних диференціальних рівнянь в частинних похідних для концентрацій одного з компонентів та точкових дефектів процедурою дискретизації зводиться до системи звичайних диференціальних рівнянь за часом. Ця система чисельно розв'язується при заданих початкових та граничних умовах за допомогою пакету прикладних програм MATLAB. Проведено моделювання радіаційно-індукованої сегрегації в двокомпонентних сплавах $\mathrm{Fe}-\mathrm{Cr}$ при різних початкових концентраціях компонентів, температурах, швидкостях утворення дефектів і набраних дозах опромінення. Продемонстрований процес досягнення стаціонарного стану при збільшенні дози опромінення. Розраховані профілі концентрації компонентів порівнюються 3 експериментально одержаними іншими авторами. Виконана оцінка чутливості моделі до вхідних параметрів та оцінюються ії можливості. Даний комп'ютерний код розвинений для багатокомпонентних сплавів.

КЛЮЧОВІ СЛОВА: матеріали реакторобудування, радіаційно-індукована сегрегація, двокомпонентні металеві сплави, профіль концентрації, точкові дефекти, обернений ефект Кіркендала, рівняння балансу, комп'ютерне моделювання

\section{МОДЕЛИРОВАНИЕ РАДИАЦИОННО-ИНДУЦИРОВАННОЙ СЕГРЕГАЦИИ В БИНАРНЫХ СПЛАВАХ Р.В. Скороход ${ }^{1}$, А.Н. Бугай ${ }^{2}$, В.Н. Билык ${ }^{2}$, В.Л. Денисенко ${ }^{2}$, А.В. Коропов ${ }^{2}$ \\ ${ }^{I}$ Харьковский национальный университет имени В.Н. Каразина пл. Свободы, 4, г. Харьков 61022, Украина \\ ${ }^{2}$ Институт прикладной физики НАН Украины \\ ул. Петропавловская, 58, г. Сумы 40030, Украина}

В модели радиационно-индуцированной сегрегации, основанной на первом и втором законах Фика с учетом обратного эффекта Киркендалла, разработан компьютерный код, с помощью которого для бинарных соединений находится пространственная и временная зависимости концентраций компонентов и точечных дефектов. Система трех связанных дифференциальных уравнений в частных производных для концентраций одного из компонентов и точечных дефектов процедурой дискретизации приводится к системе обыкновенных дифференциальных уравнений по времени. Эта система численно решается при заданных начальных и граничных условиях с помощью пакета прикладных программ MATLAB. Проведено моделирование радиационно-индуцированной сегрегации в двухкомпонентных сплавах $\mathrm{Fe}-\mathrm{Cr}$ при различных начальных концентрациях компонентов, температурах, скоростях образования дефектов и набранных дозах облучения. Продемонстрирован процесс достижения стационарного состояния при увеличении дозы облучения. Рассчитанные профили концентрации компонентов сравниваются с экспериментально полученными другими авторами. Выполнена оценка чувствительности модели к входным параметрам и оцениваются ее возможности. Данный компьютерный код разработан для многокомпонентных сплавов.

КЛЮЧЕВЫЕ СЛОВА: материалы реакторостроения, радиационно-индуцированная сегрегация, двухкомпонентные 
металлические сплавы, профиль концентрации, точечные дефекты, обратный эффект Киркендалла, уравнения баланса, компьютерное моделирование

Перехід до ядерних реакторів IV покоління $[1,2]$ вимагає удосконалення сплавів, які є конструкційними матеріалами реакторів, що потребує фундаментального розуміння еволюції їхньої мікроструктури в широкому діапазоні температур та умов опромінення [3].

Як відомо, в матеріалах, які використовуються в ядерних реакторах, нейтронне опромінювання породжує нерівноважні точкові дефекти (вакансії та міжвузельні атоми) у великих концентраціях, а також лінійні та об'ємні структурні дефекти (дислокації, пори та виділення нової фази) [3, 4].

Експерименти показують [4-13], що під час опромінення сплаву при підвищених температурах (0.3 $0.5 \mathrm{~T}_{\text {пл.) }}$ [14] відбувається просторовий перерозподіл компонентів даного сплаву. Дане явище називається радіаційно-індукованою сегрегацією і може призвести до збагачення або збіднення домішкових та легуючих елементів в областях навколо вільних поверхонь, дислокацій, пор, меж між фазами та міжзеренних меж [15]. Це викликає зміни локальних властивостей твердого тіла і сприйнятливість до процесів, які можуть негативно позначитися на механічних властивостях, корозійній стійкості тощо [16]. Дане явище певною мірою притаманне для всіх сплавів [17].

Існують два домінуючі механізми сегрегації: вакансійний і міжвузельний $[18,19]$, які виникають завдяки оберненому ефекту Кіркендала. У першому випадку потік вакансій до нерухомих стоків дефектів врівноважується протилежним за напрямком потоком атомів компонентів сплаву, в іншому випадку - потік міжвузельних атомів врівноважується потоком атомів компонентів сплаву, які мігрують як міжвузельні атоми [20].

Точкові дефекти, які виникають внаслідок опромінювання матеріалу, є рухомими і переміщуються до місць їх поглинання (стоків дефектів). Сегрегація відбувається, коли даний легуючий компонент переважно асоціюється з потоком дефектів. Збагачення або збіднення окремого елемента залежить від відносної взаємодії кожного елемента з потоком дефектів [21].

Метою роботи є розроблення комп'ютерного коду для знаходження концентраційних профілів компонентів бінарного сплаву, застосування цього коду до одержання залежностей цих профілів від температури, швидкості продукування дефектів, набраної дози, товщини плівки та порівняння 3 експериментом. Також проводиться оцінка чутливості та можливостей розглянутої моделі.

\section{БАЗОВА МОДЕЛЬ}

Розглянемо двокомпонентний сплав елементів А та В і будемо вважати, що обидві компоненти розподілені випадково по всьому зразку, який представлений тонкою плівкою товщиною 1. Вважається, що плівка обмежена площинами, які є ідеальними стоками точкових дефектів, тобто стоками такої потужності, що концентрації точкових дефектів в безпосередній близькості до стоків не змінюються при опроміненні. Також вважається, що плівка не містить об'ємних стоків точкових дефектів. В результаті опромінення при підвищених температурах локальні концентрації вакансій $C_{\mathrm{v}}$ та міжвузельних атомів $C_{i}$ змінюються з часом за законами, які для одновимірного випадку мають вигляд [15]:

$$
\begin{aligned}
& \frac{\partial C_{\mathrm{v}}}{\partial t}=-\frac{\partial}{\partial x}\left[\left(d_{A \mathrm{v}}-d_{B \mathrm{v}}\right) C_{\mathrm{v}} \alpha \Omega \frac{\partial C_{A}}{\partial x}-\left(d_{A \mathrm{v}} C_{A}+d_{B \mathrm{v}} C_{B}\right) \Omega \frac{\partial C_{\mathrm{v}}}{\partial x}\right]+K_{0}-R, \\
& \frac{\partial C_{i}}{\partial t}=-\frac{\partial}{\partial x}\left[-\left(d_{A i}-d_{B i}\right) C_{i} \alpha \Omega \frac{\partial C_{A}}{\partial x}-\left(d_{A i} C_{A}+d_{B i} C_{B}\right) \Omega \frac{\partial C_{i}}{\partial x}\right]+K_{0}-R,
\end{aligned}
$$

де $\alpha$ - термодинамічний фактор, який враховує різницю між градієнтами хімічного потенціалу та концентрації, $d_{A i}, d_{A \mathrm{v}}, d_{B i}, d_{B \mathrm{v}}$ - парціальні коефіцієнти дифузії (diffusivity coefficients [20]) елементів А та В, які дифундують за міжвузельними та вакансійними механізмами відповідно, $K_{0}$ - швидкість продукування пар Френкеля опроміненням, $R$ - швидкість рекомбінацій вакансій та міжвузельних атомів, $\Omega$ - середній атомний об'єм сплаву. Відмітимо, що $K_{0}$ залежить від типу іонізуючого випромінювання, однак в даній роботі ця величина задається довільно. Оскільки в розглянутій моделі відсутні об'ємні стоки точкових дефектів, швидкості $K_{0}$ та $R$ для міжвузельних атомів можна вважати рівними швидкостям для вакансій [15]. Для швидкості рекомбінації застосовується вираз [22]:

$$
R=4 \pi r_{i \mathrm{v}}\left[\Omega\left(d_{A \mathrm{v}}-d_{B \mathrm{v}}+d_{A i}-d_{B i}\right) C_{A}+\left(d_{B \mathrm{v}}+d_{B i}\right)\right] C_{\mathrm{v}} C_{i},
$$

де $r_{i \mathrm{v}}$ - радіус рекомбінації. В даній роботі прийнято $r_{i \mathrm{v}}=10 a$ [20], де $a$ - постійна решітки. Для компонентів А та В виконуються закони збереження речовини (рівняння балансу) [15]: 


$$
\begin{aligned}
& \frac{\partial C_{A}}{\partial t}=-\frac{\partial}{\partial x}\left[-\left(d_{A i} C_{i}-d_{A v} C_{\mathrm{v}}\right) \alpha \Omega \frac{\partial C_{A}}{\partial x}-\left(d_{A v} \frac{\partial C_{\mathrm{v}}}{\partial x}-d_{A i} \frac{\partial C_{i}}{\partial x}\right) \Omega C_{A}\right], \\
& \frac{\partial C_{B}}{\partial t}=-\frac{\partial}{\partial x}\left[-\left(d_{B i} C_{i}-d_{B \mathrm{v}} C_{\mathrm{v}}\right) \alpha \Omega \frac{\partial C_{B}}{\partial x}-\left(d_{B \mathrm{v}} \frac{\partial C_{\mathrm{v}}}{\partial x}-d_{B i} \frac{\partial C_{i}}{\partial x}\right) \Omega C_{B}\right] .
\end{aligned}
$$

Зазначимо, що у написаних вище рівняннях концентрації елементів та дефектів вимірюються числом атомів або вакансій в одиниці об' $є м у C_{m}=N_{m} / V^{t o t}$, де $N_{m}$ - число атомів чи вакансій сорту $m=A, B, \mathrm{v}, i$, а $V^{t o t}-$ об'єм сплаву. Надалі концентрацію вимірюватимемо в долях числа атомів чи вакансій по відношенню до загального числа атомів та вакансій двокомпонентного розчину $X_{m}=N_{m} / N^{\text {tot }}$, де $N^{\text {tot }}$ - сумарне число атомів сплаву. Середній атомний об'єм $\Omega=V^{\text {tot }} / N^{\text {tot }}=\frac{V^{\text {tot }} / N_{m}}{N^{\text {tot }} / N_{m}}=\frac{1 / C_{m}}{1 / X_{m}}$, звідки випливає, що доля $X_{m}=\Omega \cdot C_{m}$. Оскільки для більшості сплавів концентрації дефектів дуже малі в порівнянні з концентраціями компонентів сплаву $[17,20]$, з високим ступенем точності можна вважати, що $X_{A}+X_{B}=1$. В подальшому рівняння для елемента В не будемо наводити, тому що $X_{B}=1-X_{A}$.

\section{Початкові та граничні умови}

Для одержання розподілів атомів та точкових дефектів в часі та в просторі розв'яжемо систему зв'язаних диференціальних рівнянь (1), (2), (4) в частинних похідних, використовуючи такі початкові та граничні умови.

Розподіл концентрацій сплаву в початковий момент часу $(t=0)$ є рівномірним:

$$
\left.X_{A}(t, x)\right|_{t=0} \equiv X_{A}(0, x)=X_{A}^{0} .
$$

Концентрації дефектів $X_{\mathrm{v}}(0, x)$ i $X_{i}(0, x)$ дорівнюють концентраціям термодинамічно рівноважного стану перед опроміненням, відповідно $X_{\mathrm{v}}^{e q}$ і $X_{i}^{e q}$ :

$$
X_{\mathrm{v}}(0, x)=X_{\mathrm{v}}^{e q}, X_{i}(0, x)=X_{i}^{e q},
$$

де

$$
\begin{gathered}
X_{\mathrm{v}}^{e q}=\exp \left(\frac{S_{\mathrm{v}}^{f}}{k_{b}}\right) \exp \left(-\frac{E_{B \mathrm{v}}^{f}}{k_{b} T}\right), \\
X_{i}^{e q}=\exp \left(-\frac{E_{B i}^{f}}{k_{b} T}\right),
\end{gathered}
$$

$S_{\mathrm{v}}^{f}$ - ентропія формування вакансій, $E_{B \mathrm{v}}^{f}$ - енергія формування вакансій елемента В, $E_{B i}^{f}$ - енергія формування міжвузельних атомів елемента В.

Гранична умова при $x=0$ для точкових дефектів така:

$$
\left.\frac{\partial X_{\mathrm{v}}(\mathrm{t}, \mathrm{x})}{\partial t}\right|_{x=0}=\left.\frac{\partial X_{i}(\mathrm{t}, x)}{\partial t}\right|_{x=0}=0
$$

а в площині симетрії плівки $(x=1 / 2)$ вважаємо, що градієнти всіх концентрацій дорівнюють нулю:

$$
\left.\frac{\partial X_{A}(\mathrm{t}, x)}{\partial x}\right|_{x=\frac{1}{2} 1}=\left.\frac{\partial X_{\mathrm{v}}(\mathrm{t}, \mathrm{x})}{\partial x}\right|_{x=\frac{1}{2} 1}=\left.\frac{\partial X_{i}(\mathrm{t}, \mathrm{x})}{\partial x}\right|_{x=\frac{1}{2} 1}=0 .
$$

Для концентрації $X_{A}(t, x)$ задаємо інтегральне співвідношення, яке випливає з закону збереження речовини:

$$
\int_{0}^{1 / 2} X_{A}(t, x) d x=\frac{1}{2} X_{A}^{0} 1
$$

Співвідношення (12) відіграє роль граничної умови для компоненту сплаву А при $x=0$.

\section{Числове розв'язання рівнянь}

Замінимо просторові похідні концентрацій за допомогою процедури дискретизації у звичайний спосіб. 
Шукані концентрації обчислюються в вузлах просторової сітки $x_{n}=n \Delta x(n=0,1, \ldots, N)$, де $\Delta x-$ просторовий крок.

Першу та другу просторові похідні апроксимуємо скінченними різницями, причому для першої похідної виберемо центральну різницю: $\frac{d X_{j}}{d x}=\frac{X_{j+1}-X_{j-1}}{2 \cdot \Delta x}, \frac{d^{2} X_{j}}{d x^{2}}=\frac{X_{j+1}-2 X_{j}+X_{j-1}}{\Delta x^{2}}$.

Вводимо безрозмірні коефіцієнти дифузії

$$
d_{k l}^{*}=\frac{T \cdot d_{k l}}{L^{2}}
$$

де індекси $k=A$ або $B$, а $l=\mathrm{v}$ або $i, T=D / K_{0}, D-$ доза опромінення, $L=\frac{1}{2}+\frac{\Delta x}{2}, \Delta x=\frac{L}{N+1}$, а також безрозмірний час $\tau=\frac{t}{T}$. Змінимо концентрації дефектів таким чином, щоб їх значення стали одного порядку з концентраціями компонентів $X_{A}, X_{B}$ :

$$
\begin{gathered}
V=d_{A \mathrm{v}}^{*} \cdot X_{\mathrm{v}}, \\
I=d_{A i}^{*} \cdot X_{i} .
\end{gathered}
$$

Остаточно одержимо систему рівнянь для часової еволюції концентрацій, яка є жорсткою [23, 24] через велику різницю парціальних коефіцієнтів дифузії.

Часова еволюція концентрацій матеріалу А визначається такими рівняннями:

$$
\begin{aligned}
& \frac{\partial X_{A j}}{\partial \tau}=\frac{(\alpha-1)(N+1)^{2}}{4}\left[X_{A j+1} V_{j+1}-X_{A j-1} V_{j+1}-X_{A j+1} V_{j-1}+X_{A j-1} V_{j-1}\right] \\
& +\frac{(\alpha+1)}{4}(N+1)^{2}\left[X_{A j+1} I_{j+1}-X_{A j-1} I_{j+1}-X_{A j+1} I_{j-1}+X_{A j-1} I_{j-1}\right] \\
& +\alpha(N+1)^{2}\left[X_{A j+1} V_{j}-2 X_{A j} V_{j}+X_{A j-1} V_{j}\right]+\alpha(N+1)^{2}\left[X_{A j+1} I_{j}-2 X_{A j} I_{j}+X_{A j-1} I_{j}\right] \\
& -(N+1)^{2}\left[X_{A j} V_{j+1}-2 X_{A j} V_{j}+X_{A j} V_{j-1}\right]+(N+1)^{2}\left[X_{A j} I_{j+1}-2 X_{A j} I_{j}+X_{A j} I_{j-1}\right],
\end{aligned}
$$

де $j=1,2, \ldots, N$. Часова еволюція концентрацій вакансій визначається подібними рівняннями 3 додаванням членів, які описують швидкість продукування дефектів та швидкість рекомбінацій:

$$
\begin{aligned}
& \frac{\partial V_{j}}{\partial \tau}=\frac{(1-\alpha)(N+1)^{2}}{4}\left(d_{A \mathrm{v}}^{*}-d_{B \mathrm{v}}^{*}\right)\left[X_{A j+1} V_{j+1}-X_{A j-1} V_{j+1}-X_{A j+1} V_{j-1}+X_{A j-1} V_{j-1}\right] \\
& +\left(d_{A \mathrm{v}}^{*}-d_{B \mathrm{v}}^{*}\right)(N+1)^{2}\left[X_{A j} V_{j+1}-2 X_{A j} V_{j}+X_{A j} V_{j-1}\right]+d_{B \mathrm{v}}^{*}(N+1)^{2}\left[V_{j+1}-2 V_{j}+V_{j-1}\right] \\
& -\alpha(N+1)^{2}\left(d_{A \mathrm{v}}^{*}-d_{B \mathrm{v}}^{*}\right)\left[X_{A j+1} V_{j}-2 X_{A j} V_{j}+X_{A j-1} V_{j}\right]+d_{A \mathrm{v}}^{*} D \\
& -\frac{4 \pi r_{i \mathrm{v}} L^{2}}{\Omega d_{A i}^{*}}\left[\left(d_{A \mathrm{v}}^{*}-d_{B \mathrm{v}}^{*}+d_{A i}^{*}-d_{B i}^{*}\right) X_{A j}+d_{B \mathrm{v}}^{*}+d_{B i}^{*}\right] V_{j} I_{j} .
\end{aligned}
$$

Часова еволюція концентрацій міжвузельних атомів визначається аналогічними рівняннями:

$$
\begin{aligned}
& \frac{\partial I_{j}}{\partial \tau}=\frac{(\alpha+1)(N+1)^{2}}{4}\left(d_{A i}^{*}-d_{B i}^{*}\right)\left[X_{A j+1} I_{j+1}-X_{A j-1} I_{j+1}-X_{A j+1} I_{j-1}+X_{A j-1} I_{j-1}\right] \\
& +\left(d_{A i}^{*}-d_{B i}^{*}\right)(N+1)^{2}\left[X_{A j} I_{j+1}-2 X_{A j} I_{j}+X_{A j} I_{j-1}\right]+d_{B i}^{*}(N+1)^{2}\left[I_{j+1}-2 I_{j}+I_{j-1}\right] \\
& +\alpha(N+1)^{2}\left(d_{A i}^{*}-d_{B i}^{*}\right)\left[X_{A j+1} I_{j}-2 X_{A j} I_{j}+X_{A j-1} I_{j}\right]+d_{A i}^{*} D \\
& -\frac{4 \pi r_{i \mathrm{v}} L^{2}}{\Omega d_{A \mathrm{v}}^{*}}\left[\left(d_{A \mathrm{v}}^{*}-d_{B \mathrm{v}}^{*}+d_{A i}^{*}-d_{B i}^{*}\right) X_{A j}+d_{B \mathrm{v}}^{*}+d_{B i}^{*}\right] V_{j} I_{j} .
\end{aligned}
$$

Числове інтегрування одержаної системи рівнянь проведено за допомогою пакету прикладних програм MATLAB з використанням програмного коду ode15s. При моделюванні використані значення параметрів, які наведені в літературних джерелах (Таблиця). Відмітимо, що даний комп'ютерний код можна поширити на багатокомпонентні сплави $[16,20,25]$, додавши один, два і т.д. закони збереження для компонентів. 
Вхідні параметри

\begin{tabular}{|c|c|c|c|}
\hline Визначення & Символ & Значення & Посилання \\
\hline Енергія формування міжвузельних атомів Fe & $E_{F e, i}^{f}$ & $5,0 \mathrm{eB}$ & {$[26]$} \\
\hline Енергія формування вакансій Fе & $E_{F e, \mathrm{v}}^{f}$ & $1,6 \mathrm{eB}$ & {$[27]$} \\
\hline Енергія міграції міжвузельних атомів $\mathrm{Fe}$ & $E_{F e, i}^{m}$ & $0,35 \mathrm{eB}$ & {$[28]$} \\
\hline Енергія міграції вакансій Fе & $E_{F e, \mathrm{v}}^{m}$ & $0,625 \mathrm{eB}$ & {$[28,29]$} \\
\hline Передекспоненціальний фактор дифузії міжвузельних & $d_{0 F, i}$ & $6,59 \times 10^{-7} \mathrm{~m}^{2} / \mathrm{c}$ & {$[30]$} \\
\hline атомів в Fе & $d_{0 F e, \mathrm{v}}$ & $5,92 \times 10^{-6} \mathrm{~m}^{2} / \mathrm{c}$ & {$[30]$} \\
\hline Передекспоненціальний фактор дифузії вакансій $\mathrm{Fe}$ & $E_{C r, i}^{m}$ & $0,28 \mathrm{eB}$ & {$[28]$} \\
\hline Енергія міграції міжвузельних атомів $\mathrm{Cr}$ & $E_{C r, \mathrm{v}}^{m}$ & $0,55 \mathrm{eB}$ & {$[28]$} \\
\hline Енергія міграції вакансій Сr & $d_{0 C r, i}$ & $6,85 \times 10^{-7} \mathrm{~m}^{2} / \mathrm{c}$ & {$[30]$} \\
\hline Передекспоненціальний фактор дифузії міжвузельних \\
атомів Сг & $d_{0 C r, \mathrm{v}}$ & $5,46 \times 10^{-6} \mathrm{~m}^{2} / \mathrm{c}$ & {$[30]$} \\
\hline Передекспоненціальний фактор дифузії вакансій $\mathrm{Cr}$ & $S_{\mathrm{v}}^{f}$ & $1,0 \mathrm{k}_{\mathrm{b}}$ & {$[31]$} \\
\hline Ентропія формування вакансій & $\alpha$ & 1,0 & \\
\hline Термодинамічний фактор & & & \\
\hline
\end{tabular}

Чутливість моделі

Чутливість моделі будемо визначати як похідну $\partial X / \partial p$ концентрації $\mathrm{Cr}$ на межі плівки від вхідного параметра $p$ (див. табл.) [28, 29, 31], яку можна апроксимувати наступним чином:

$$
\frac{\partial X}{\partial p} \approx \frac{\delta X}{\delta p}=\frac{X^{\prime}-X_{\text {reference }}}{p^{\prime}-p_{\text {reference }}},
$$

де $X_{\text {reference }}-$ концентрація $\mathrm{Cr}$ на поверхні плівки, що розраховується при $p_{\text {reference }}, X^{\prime}-$ концентрація Сr на поверхні плівки, що розраховується при $p^{\prime}\left(\left|X^{\prime}-X_{\text {reference }}\right|<<X_{\text {reference }},\left|p^{\prime}-p_{\text {reference }}\right|<<p_{\text {reference }}\right)$.

Від чутливості зручно перейти до значущості, $S_{p}^{X}$, яка є відносною зміною розрахованої концентрації Сr на поверхні плівки по відношенню до відносної зміни вхідного параметра:

$$
S_{p}^{X}=\frac{X^{\prime}-X_{\text {reference }}}{p^{\prime}-p_{\text {reference }}} \cdot \frac{p_{\text {reference }}}{X_{\text {reference }}} .
$$

Зрозуміло, що концентрація $\mathrm{Cr}$ на поверхні плівки найбільш чутлива до тих параметрів, які мають найбільшу значущість.

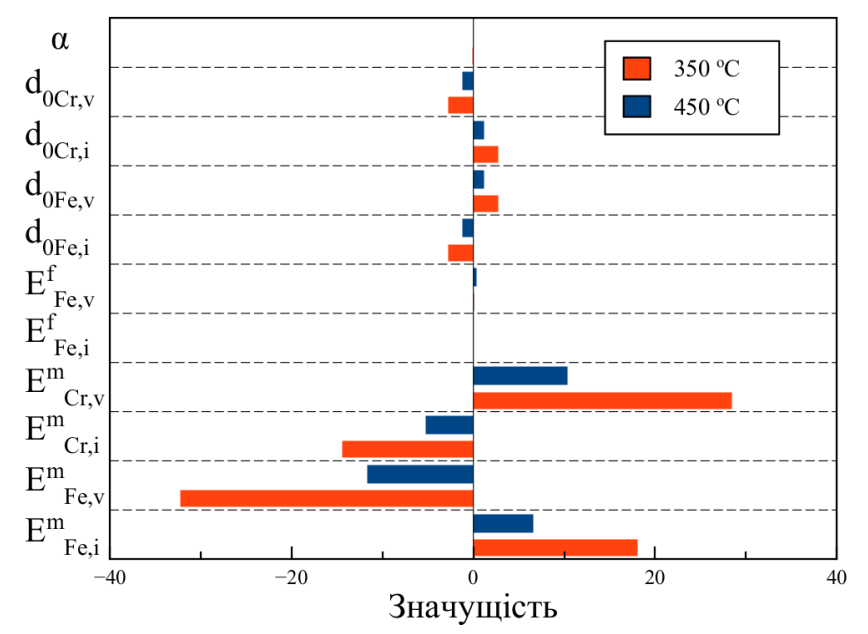

Рис. 1. Результати аналізу чутливості даної моделі
Значущість була розрахована шляхом моделювання опромінювання сплаву $\mathrm{Fe}-9 \mathrm{Cr}$ до дози 1 зна для двох температур $350^{\circ} \mathrm{C}$ та $450^{\circ} \mathrm{C}$ при швидкості продукування дефектів $10^{-5}$ зна.c ${ }^{-1}$. Зауважимо, що на відміну від дозиметрії, де використовується в якості одиниці вимірювання дози 1 Грей, в фізиці радіаційних ушкоджень використовується одиниця дози в 1 зна (зміщень на атом). Це пов'язано 3 тим, що в радіаційному матеріалознавстві головним результатом опромінювання матеріалу $\epsilon$ зміщення атомів матеріалу 3 вузлів гратки. Результати розрахунків подані на рис. 1. Концентрація $\mathrm{Cr}$ на поверхні плівки найбільш чутлива до енергій міграцій вакансій i міжвузельних атомів $\mathrm{Fe}$ та $\mathrm{Cr}$. Підвищення температури призводить до суттєвого зменшення значущості параметрів, що, ймовірно, викликано збільшенням зворотної дифузії. 


\section{РЕЗУЛЬТАТИ ТА ОБГОВОРЕННЯ}

Проведено моделювання опромінювання плівки $\mathrm{Fe}-8.3 \mathrm{mac.} \% \mathrm{Cr}$ та плівки $\mathrm{Fe}-9$ мас. \% $\mathrm{Cr}$ до дози 1 зна за сталої швидкості продукування дефектів $10^{-5}$ зна/с, товщини 300 нм і температури $400^{\circ} \mathrm{C}$. Розраховані профілі концентрації $\mathrm{Cr}$ порівнюються з експериментально одержаними на межах зерен у сплавах $\mathrm{T} 91$ (рис. 2) та $\mathrm{Fe}-$ 9мас. \%Cr (рис. 3) [13], відповідно. Як було вказано в постановці задачі, профіль концентрації Сr був розрахований для лівої половини плівки $(0 \leq x \leq 1 / 2)$. Для співставлення з експериментом праву частину розрахованого профілю $\mathrm{Cr}(1 / 2 \leq x \leq 1)$, який є дзеркально симетричним відносно площини $x=1 / 2$, ми розмістили 3 лівого боку від міжзеренної межі. Розрахований профіль концентрації сплаву $\mathrm{Fe}-8.3 \mathrm{Mac} . \% \mathrm{Cr}$ задовільно узгоджується з експериментальним. Одержана величина збагачення Сr у сплаві Fe-9мас. \%Cr більша за експериментальну, що пов'язано з тим, що енергії міграції точкових дефектів $\mathrm{Fe}$ та $\mathrm{Cr}$ змінюються зі зміною концентрації $\mathrm{Cr}$ в сплавах $\mathrm{Fe}-\mathrm{Cr}[3,28,32]$.

\section{Залежність від дози. Стаціонарний стан}

На рис. 4 наведені залежності концентрації $\mathrm{Cr}$ від відстані до поверхні для плівки $\mathrm{Fe}-9 \mathrm{aT.} \% \mathrm{Cr}$ товщиною 300 нм за сталої швидкості продукування дефектів $10^{-5}$ зна/с та температури $400^{\circ} \mathrm{C}$. Ці залежності відрізняються дозами опромінення, а саме $10^{-3}$ зна, $10^{-2}$ зна, $10^{-1}$ зна і 1 зна. Зі збільшенням дози криві прямують до верхньої 3 зображених кривих - стаціонарного стану, який для заданих умов настає при дозі опромінення, рівній 1 зна. В процесі опромінення крутизна профілю концентрації $\mathrm{Cr}$ зменшується, значення збагачення $\mathrm{Cr}$ збільшується.

Характерною особливістю стаціонарного стану є рівність нулю потоків компонентів та рівність потоків вакансій потокам міжвузельних атомів для кожної точки простору. Для цього стану, як можна показати, градієнт концентрації компонента А пов'язаний з градієнтом концентрації вакансій таким співвідношенням [13]:

$$
\nabla X_{A}=\frac{X_{A} X_{B} d_{B \mathrm{v}} d_{B i}}{\alpha\left(d_{B i} X_{B}\left(d_{A \mathrm{v}} X_{\mathrm{v}}+d_{A i} X_{i}\right)+d_{A i} X_{A}\left(d_{B \mathrm{v}} X_{\mathrm{v}}+d_{B i} X_{i}\right)\right)}\left(\frac{d_{A \mathrm{v}}}{d_{B \mathrm{v}}}-\frac{d_{A i}}{d_{B i}}\right) \nabla X_{\mathrm{v}} .
$$

3 рівності (21) випливає, що збагачення чи збіднення компоненту А визначається знаком різниці відношень коефіцієнтів дифузії за вакансійним механізмом $\left(d_{A v} / d_{B v}\right)$ та міжвузельним механізмом $\left(d_{A i} / d_{B \mathrm{i}}\right)$. Наприклад, якщо $d_{A i} / d_{B \mathrm{i}}>d_{A v} / d_{B \mathrm{v}}$, то на поверхні буде спостерігатися збагачення компоненту А.

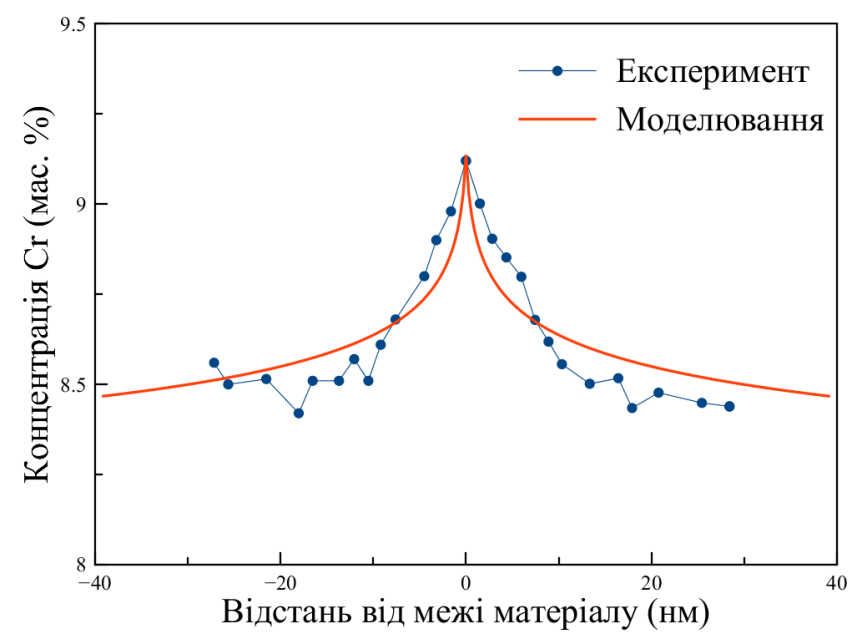

Рис. 2. Експериментальний профіль концентрації $\mathrm{Cr}$ в залежності від відстані до межі зерна у сплаві Т91, який опромінений до дози 1 зна при температурі $400^{\circ} \mathrm{C}$ та швидкості продукування дефектів $1,2 \cdot 10^{-5}$ зна/с [13] - синя крива, та модельований профіль концентрації $\mathrm{Cr}$ у плівці $\mathrm{Fe}-$ 8.3 мас. \%Сr товщиною 300 нм за тих же умов - червона крива

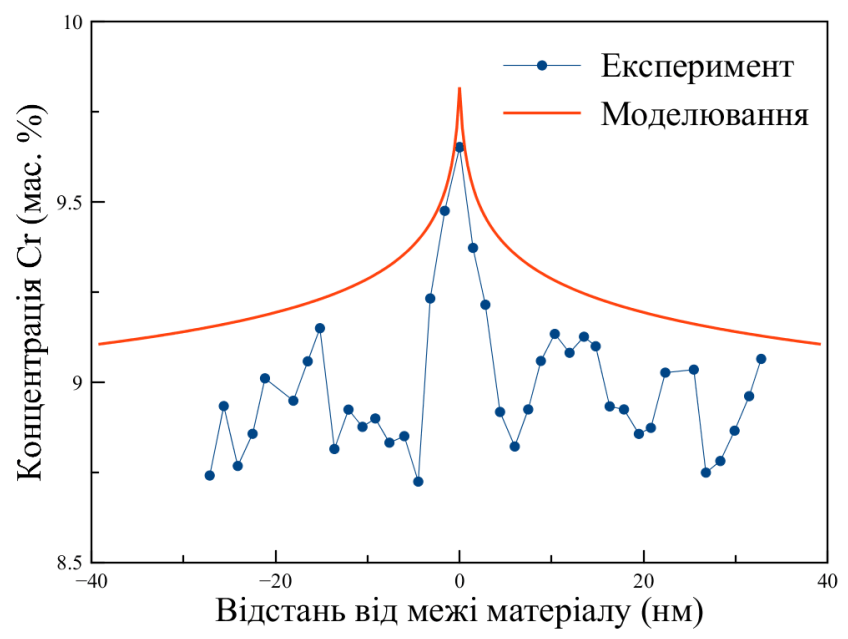

Рис. 3. Експериментальний профіль концентрації $\mathrm{Cr}$ в залежності від відстані до межі зерна у сплаві Fе-9мас. \%Cr, який опромінений до дози 1 зна при температурі $400^{\circ} \mathrm{C}$ та швидкості продукування дефектів $1,2 \cdot 10^{-5}$ зна/с [13] - синя крива, та модельований профіль концентрації $\mathrm{Cr}$ у плівці $\mathrm{Fe}-$ 9 мас. \%Сr товщиною 300 нм за тих же умов - червона крива

\section{Залежності збагачення Сr від температури, товщини плівки та швидкості продукування дефектів}

Розглянемо дві моделі: поточну модель 3 термодинамічно рівноважними граничними умовами та модель абсолютно чорних стоків дефектів (АЧСД), в якій концентрації вакансій та міжвузельних атомів в безпосередній близькості до стоків рівні нулю [29].

Подамо розраховану залежність збагачення $\mathrm{Cr}$ (приріст концентрації $\mathrm{Cr}$ на поверхні плівки) від температури для плівки $\mathrm{Fe}-9$ ат. \%Cr товщиною 300 нм при дозі 1 зна за сталої швидкості продукування дефектів $10^{-5}$ зна/с для термодинамічно рівноважної моделі і моделі АЧСД рис. 5 . 


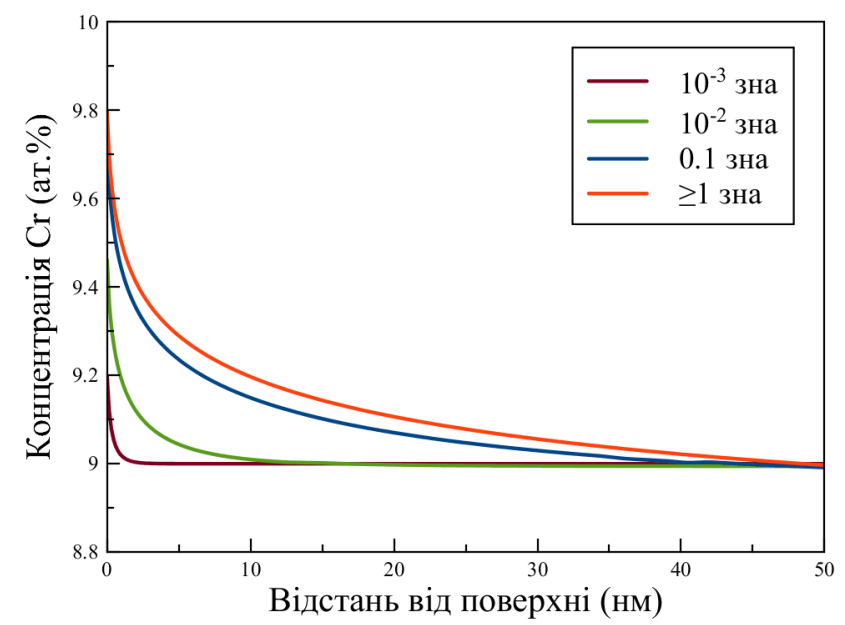

Рис. 4. Профілі концентрації Сr в процесі опромінювання до досягнення стаціонарного стану.

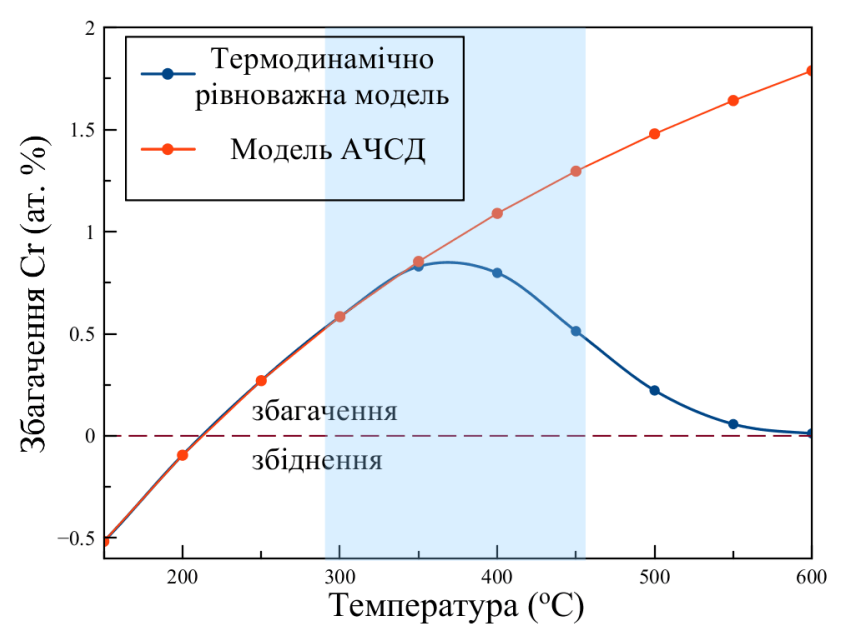

Рис. 5. Залежність збагачення Сr від температури

Оскільки при температурі $\mathrm{T}=211^{\circ} \mathrm{C}$ вираз $\frac{d_{A v}}{d_{B v}}-\frac{d_{A i}}{d_{B i}}$ в формулі (21) змінює знак, це означає, що має місце перехід від збіднення $\mathrm{Cr}$ до збагачення $\mathrm{Cr}$ на поверхні плівки. При температурі $370^{\circ} \mathrm{C}$ для моделі 3 термодинамічно рівноважними граничними умовами спостерігається максимум збагачення Сr як функції температури. Зі збільшенням температури збагачення $\mathrm{Cr}$ зменшується до нуля, що пояснюється зростанням термодинамічно рівноважних значень концентрацій точкових дефектів, а отже і зростанням зворотної дифузії. Заштрихована область відповідає діапазону температур, для якого збагачення Сr задовільно узгоджується 3 експериментальним $\left(\approx 300^{\circ} \mathrm{C}-450^{\circ} \mathrm{C}\right)$. Стосовно моделі АЧСД можна стверджувати, що зі збільшенням температури Т зростає коефіцієнт рекомбінації, внаслідок чого приріст збагачення Сr зменшується.

Для одержання залежності збагачення $\mathrm{Cr}$ від товщини плівки проведено моделювання опромінювання плівок Fe-9ат. \%Cr різної товщини до дози 1 зна за сталої швидкості продукування дефектів $10^{-5}$ зна/с та температури $400^{\circ} \mathrm{C}$ для термодинамічно рівноважної моделі і моделі АЧСД. Результати моделювання представлені на рис. 6.

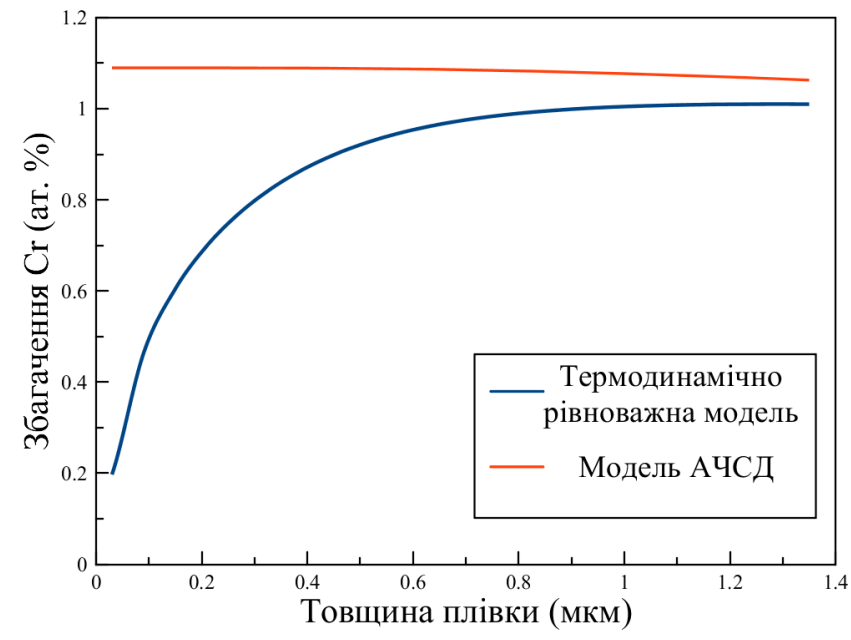

Рис. 6. Залежність збагачення Сr від товщини плівки

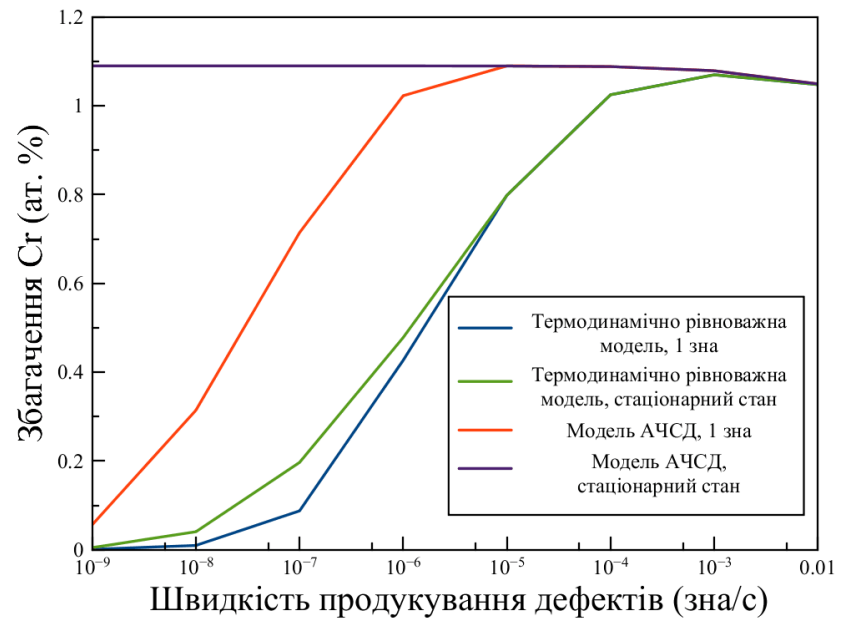

Рис. 7. Залежність збагачення Сr від швидкості продукування дефектів

У випадку термодинамічно рівноважної моделі збільшення товщини плівки приводить до збільшення збагачення Cr, що пов’язано зі збільшенням кількості продукованих дефектів, які переносяться до поверхні. Як видно з рис. 6, при малих товщинах плівки приріст збагачення Сr відносно значний, в подальшому цей приріст сповільнюється, що, ймовірно, пов'язано з тим, що рушійні сили дифузії (пропорційні градієнтам концентрації) можуть забезпечити лише певну максимальну швидкість процесу. В моделі АЧСд збагачення Сr слабко залежить від товщини плівки, незначно зменшуючись зі збільшенням товщини (див. рис. 6).

На рис. 7 наведена залежність збагачення $\mathrm{Cr}$ від швидкості продукування дефектів плівки $\mathrm{Fe}-9 \mathrm{aT}$. \% $\mathrm{Cr}$ товщиною 300 нм при дозі 1 зна і стаціонарному стані за температури $400^{\circ} \mathrm{C}$ для термодинамічно рівноважної моделі та моделі АЧСД. 
В термодинамічно рівноважній моделі спостерігається максимум збагачення $\mathrm{Cr}$ як функція швидкості продукування дефектів $K_{0}$, оскільки має місце конкуренція двох процесів: збільшення відносної концентрації дефектів $\left(X_{\mathrm{i}, \mathrm{v}}-X_{\mathrm{i}, \mathrm{v}}^{e q}\right)$ приводить до збільшення збагачення $\mathrm{Cr}$, а збільшення коефіцієнта рекомбінації $R$ приводить до зменшення збагачення $\mathrm{Cr}$ (зелена крива на рис. 7, яка демонструє максимум при $K_{0}=10^{-3}$ ). Для моделі АЧСД при досягненні стаціонарного стану спостерігається зменшення збагачення Сr зі збільшенням $K_{0}$ за рахунок збільшення $R$. Як випливає з наших розрахунків, доза опромінення, за якої настає стаціонарний стан, зменшується зі збільшенням швидкості продукування дефектів (рис. 7).

Розраховані нами залежності збагачення $\mathrm{Cr}$ від температури та швидкості продукування дефектів подібні до опублікованих раніше [15, 20, 28, 29]. Залежність збагачення Сr від товщини плівки розглядається вперше.

\section{ВИСНОВКИ}

На базі пакету прикладних програм MATLAB розроблений комп’ютерний код для чисельного розв'язку системи диференціальних рівнянь, які описують радіаційно-індуковану сегрегацію в бінарних сплавах. В результаті моделювання були одержані концентраційні профілі $\mathrm{Cr}$ в сплавах $\mathrm{Fe}-\mathrm{Cr}$ при різних дозах опромінення, температурах, товщинах плівки і швидкостях продукування точкових дефектів та побудовані залежності збагачення $\mathrm{Cr}$ від температури, товщини плівки i швидкості продукування дефектів для термодинамічно рівноважної моделі та моделі АЧСД. Для стаціонарного стану знак збагачення компоненту А збігається зі знаком різниці відношень коефіцієнтів дифузії за міжвузельним механізмом та вакансійним механізмом $\left(d_{A i} / d_{B \mathrm{i}}-d_{A \mathrm{v}} / d_{B \mathrm{v}}\right)$.

Проведений аналіз чутливості обраної моделі від вхідних параметрів показав, що сегрегація найбільш суттєво залежить від енергій міграції вакансій та міжвузельних атомів Fe та Cr. Підвищення температури призводить до зменшення значущості параметрів.

Як показує порівняння розрахованих профілів концентрації $\mathrm{Cr} 3$ експериментально одержаними, використана модель задовільно описує процес радіаційно-індукованої сегрегації в двокомпонентних сплавах $\mathrm{Fe}-\mathrm{Cr}$ при дозах опромінення нижчих 1 зна та температурах від $300^{\circ} \mathrm{C}$ до $450^{\circ} \mathrm{C}$.

Одержані результати є складовою частиною наукової роботи №217-16 (договір №K-3-54/2016 на виконання наукової роботи) PK 0116 U002993 «Дослідження радіаційних дефектів та радіаційно-індукованої сегрегації домішок в сплавах цирконію під дією опромінення іонами 3 використанням методів ядерного мікроаналізу» (науковий керівник - академік НАН України, професор Сторіжко В.Ю.)

\section{СПИСОК ЛІТЕРАТУРИ}

1. Buckthorpe D. Introduction to Generation IV nuclear reactors // In Woodhead Publishing Series in Energy: N.106. Structural Materials for Generation IV Nuclear Reactors / Ed. by P. Yvon - Amsterdam: Elsevier Ltd., 2017. - P. 1-22.

2. Aitkaliyeva A., He L., Wen H., Miller B., Bai X.M., Allen T. Irradiation effects in Generation IV nuclear reactor materials // In Woodhead Publishing Series in Energy: N.106. Structural Materials for Generation IV Nuclear Reactors / Ed. by P. Yvon Amsterdam: Elsevier Ltd., 2017. - P. 253-283.

3. Choudhury S., Barnard L., Tucker J.D., Allen T.R., Wirth B.D., Asta M., Morgan D. Ab-initio based modeling of diffusion in dilute bcc Fe-Ni and Fe-Cr alloys and implications for radiation induced segregation // J. Nucl. Mater. - 2011. - Vol. 411. - P. $1-14$.

4. Lu Z., Faulkner R.G., Was G., Wirth B.D. Irradiation-induced grain boundary chromium microchemistry in high ferritic steels // Scr. Mater. - 2008. - Vol. 58. - P. 878-881.

5. Takahashi H., Ohnuki S., Takeyama T. Radiation-induced segregation at internal sinks in electron irradiated binary alloys // J. Nucl. Mater. - 1981. - Vol. 103-104. - P. 1415-1420.

6. Little E.A., Morgan T.S., Faulkner R.G. Microchemistry of neutron irradiated $12 \% \mathrm{CrMoVNb}$ martensitic steel // Mater. Sci. Forum. - 1992. - Vol. 97-99 - P. 323-328.

7. Neklyudov I.M., Voyevodin V.N. Features of structure-phase transformations and segregation processes under irradiation of austenitic and ferritic-martensitic steels // J. Nucl. Mater. - 1994. - Vol. 212-215. - P. 39-44.

8. Schaeublin R., Spatig P., Victoria M. Chemical segregation of the low activation ferritic/martensitic steel F82H // J. Nucl. Mater. - 1998. - Vol. 263. - P. 1350-1355.

9. Gupta G., Jiao Z., Ham A.N., Busby J.T., Was G.S. Microstructural evolution of proton irradiated T91 // J. Nucl. Mater. - 2006. - Vol. 351. - P. 162-173.

10. Lu Z., Faulkner R.G., Sakaguchi N., Kinoshita H., Takahashi H., Flewitt P.E.J. Effect of hafnium on radiation-induced intergranular segregation in ferritic steel // J. Nucl. Mater. - 2006. - Vol. 351. - P. 155-161.

11. Marquis E.A., Lozano-Perez S., de Castro V. Effects of heavy-ion irradiation on the grain boundary chemistry of an oxidedispersion strengthened Fe-12 wt.\% Cr alloy // J. Nucl. Mater. - 2011. - Vol. 417. - P. 257-261.

12. Marquis E.A., Hu R., Rousseau T., A systematic approach for the study of radiation-induced segregation/depletion at grain boundaries in steel // J. Nucl. Mater. - 2011. - Vol. 413. - P. 1-4.

13. Wharry J.P., Was G.S. A systematic study of radiation-induced segregation in ferritic-martensitic alloys // J. Nucl. Mater. 2013. - Vol. 442. - P. 7-16. 
14. Okamoto P.R., Rehn L.E. Radiation-induced segregation in binary and ternary alloys // J. Nucl. Mater. - 1979. - Vol. 83. - P. $2-23$.

15. Wiedersich H., Okamoto P.R., Lam N.Q. A theory of radiation-induced segregation in concentrated alloys // J. Nucl. Mater. 1979. - Vol. 83. - P. 98-108.

16. Watanabe S., Takahashi H. Discriminant of RIS in multi-component alloys // J. Nucl. Mater. - 1994. - Vol. 208. - P. 191-194.

17. Marwick A.D. Calculation of bias due to solute redistribution in an irradiated binary alloy: surfaces of a thin foil // J. Nucl. Mater. - 1985. - Vol. 135. - P. 68-76.

18. Voyevodin V.N., Neklyudov I.M. Evolution of the structure phase state and radiation resistance of structural materials. - Kiev: Naukova dumka, 2006. - 376 p. (in Russian)

19. Voyevodin V.N. Structural materials of nuclear power - challenge to 21 century // Problems of Atomic Science and Technology. - 2007. - Vol. 90. - P. 10-22. (in Russian)

20. Was G.S. Fundamentals of Radiation Materials Science: Metals and Alloys. - New York: University of Michigan, Springer, 2007. -828 p.

21. Was G.S., Wharry J.P., Frisbie B., Wirth B.D., Morgan D., Tucker J.D., Allen T.R. Assessment of radiation-induced segregation mechanisms in austenitic and ferritic-martensitic alloys // J. Nucl. Mater. - 2011. - Vol. 411. - P. 41-50.

22. Xu D., Wirth B.D., Li M., Kirk M.A. Combining in situ transmission electron microscopy irradiation experiments with cluster dynamics modeling to study nanoscale defect agglomeration in structural metals // Acta Mater. - 2012. - Vol. 60. - P. 42864302.

23. Hairer E., Wanner G. Solving Ordinary Differential Equations II: Stiff and Differential-Algebraic Problems. - 2nd edn. Berlin, Springer, 1996. -614 p.

24. Shampine L.F., Reichelt M.W. The MATLAB ODE suite // SIAM J. Sci. Comput. - 1997. - Vol. 18. - No. 1. - P. 1-22.

25. Koropov O.V. Differential equations of radiation-induced segregation in five-component metal alloys // Proc. of Eighteenth International Scientific Mykhailo Kravchuk Conference, October 7-10, 2017, Kyiv: Vol. 1. - Kyiv: NTUU "KPI”, 2017. P. 86 - 90. (in Ukrainian)

26. Olsson P., Domain C., Wallenius J. Ab initio study of Cr interactions with point defects in bcc Fe // Phys Rev B. - 2007. - Vol. 75. - P. 014110.

27. Schaefer H.-E., Maier K., Weller M., Herlach D., Seeger A., Diehl J. Vacancy formation in iron investigated by positron annihilation in thermal equilibrium // Scripta Metallurgica. - 1977. - Vol. 11. - P. 803-809.

28. Wharry J.P., Was G.S. The mechanism of radiation-induced segregation in ferritic-martensitic alloys // Acta Mater. - 2014. Vol. 65. - P. 42-55.

29. Selby A.P. Modeling Radiation-Induced Segregation in Ferritic-Martensitic Steels. Master's Thesis. - University of Tennessee, 2015.

30. Field K.G., Barnard L.M., Parish C.M., Busby J.T., Morgan D., Allen T.R. Dependence on grain boundary structure of radiation induced segregation in a $9 \mathrm{wt} . \% \mathrm{Cr}$ model ferritic/martensitic stell // J. Nucl. Mater. - 2013. - Vol. 435. - P. 172-180.

31. Allen T.R., Was G.S. Modeling radiation-induced segregation in austenitic Fe-Cr-Ni alloys // Acta Mater. - 1998. - Vol. 46. No. 10. - P. 3679-3691.

32. Terentyev D., Olsson P., Klaver T.P.C., Malerba L. On the migration and trapping of single self-interstitial atoms in dilute and concentrated $\mathrm{Fe}-\mathrm{Cr}$ alloys: Atomistic study and comparison with resistivity recovery experiments // Computational Materials Science. - 2008. - Vol. 43. - P. 1183-1192. 